\title{
HUMORAL IMMUNE RESPONSE TO ANTIGENS OF Porphyromonas gingivalis ATCC 33277 IN CHRONIC PERIODONTITIS
}

\author{
Mônica FRANCA 1 , Lília MOURA-COSTA², Roberto J. MEYER ${ }^{3}$, Soraya C. TRINDADE \\ Urbino da Rocha TUNES ${ }^{5}$, Songelí M. FREIRE ${ }^{6}$
}

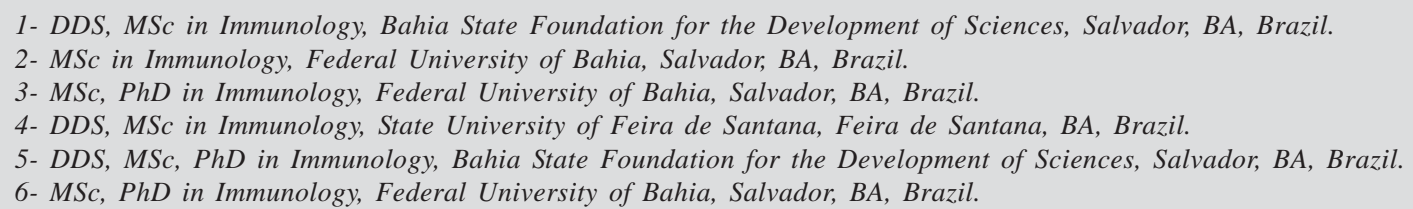

Corresponding address: Profa. Mônica Franca - Rua Catarina Paraguassu n 365, ap. 1302, 40140-200, Graça, Salvador, BA, Brasil Fax: 557133584676 - e-mail: monfranca@yahoo.com.br

Received: November 30, 2006 - Modification: February 08, 2007 - Accepted: May 07, 2007

\begin{abstract}
$I_{\text {ntroduction: Periodontitis is a chronic disease that results from an interaction of a mixed bacterial challenge and the host }}$ response. Objective: The purposes of this study were to evaluate the IgG serum levels to Porphyromonas gingivalis antigens by ELISA in individuals with different periodontal conditions correlated with clinical parameters, and to analyze the immunoreactivity profiles by Western blotting. Methods: Serum IgG levels against the cell sonicate antigen from $P$. gingivalis ATCC 33277 of 28 patients with chronic periodontitis (CP), 10 patients with gingivitis (G) and 21 periodontally healthy individuals $(\mathrm{H})$ were measured by ELISA and Western immunoblotting. Results: In the CP group, sera reactivity by ELISA was significantly higher than in the $\mathrm{G}$ and $\mathrm{H}$ groups (Kruskal-Wallis $\mathrm{p}<0.001$; Dunnet $\mathrm{t} 3 \mathrm{p}=0.001$ and Dunnet $\mathrm{t} 3 \mathrm{p}=0.0001$ ). There was no statistically significant difference between $\mathrm{G}$ and HP reactivity (Dunnett $\mathrm{t} 3 \mathrm{p}=0.617$ ). Among individuals with chronic periodontitis, the IgG-anti-P. gingivalis serum levels were positively correlated with percentage of clinical attachment level $=5 \mathrm{~mm}\left(\mathrm{r}_{\mathrm{s}}=+0.375, \mathrm{p}<0.05\right)$ and a negative correlation was found between IgG-anti-P. gingivalis levels and percentage of probing pocket depth $0-3 \mathrm{~mm}\left(\mathrm{r}_{\mathrm{s}}=-0.411, \mathrm{p}<0.05\right)$. The analysis of sera immunoreactivity profiles to sonicate antigen by Western blotting showed differences between the sera of CP, G and H group individuals. The serum from CP frequently reacted with high molecular weight (103 kDa, 86 kDa, 72 kDa, 60 kDa, 58 kDa, 52 kDa) protein fractions. Conclusions: Serum levels of IgG anti- $P$. gingivalis distinguished individuals with chronic periodontitis, gingivitis and healthy periodontium. There was a correlation between clinical parameters and serum IgG levels against $P$. gingivalis. There was a difference in the recognition profile of protein fractions among the studied groups and some bands were more specific
\end{abstract}

Uniterms: Periodontitis; Porphyromonas gingivalis; ELISA; Western blotting; Immunoglobulin G.

\section{INTRODUCTION}

Periodontitis clearly is a multifactorial disease that appears as a result of a combination of parameters including genetic susceptibility, challenge by specific pathogens and host's inflammatory and immune response characteristics ${ }^{12,13}$. The finding that bacteria that predominate at sites of existing periodontal destruction are also encountered at quiescent sites implies that periodontal destruction is the consequence of a disturbance between the subgingival microflora and the host defense system ${ }^{13}$. The existence of systemic humoral immune response to a variety of oral bacteria is well documented in subjects with different forms of periodontal disease ${ }^{2,15}$. According to van Dyke and Sheilesh ${ }^{15}$ (2005), it is now widely accepted that susceptibility to periodontitis varies greatly between individuals that harbor the same pathogenic microflora. In particular, several studies have demonstrated an elevated level of serum immunoglobulins reactive to Porphyromonas gingivalis, suspected of being a major periodontal pathogen in adult individuals with chronic periodontitis, as compared to healthy subjects ${ }^{8,10}$. The aims of this study were to compare the IgG serum levels to $P$. gingivalis cell sonicate antigen by ELISA among individuals with chronic periodontitis (CP), healthy periodontium $(\mathrm{H})$ and gingivitis $(G)$, to analyze the sera immunoreactive profiles to sonicate 
antigen by Western blotting, and to compare the levels of IgG to clinical parameters in the chronic periodontitis group.

\section{MATERIALAND METHODS}

\section{Subjects}

The study population was as follows: 28 individuals with chronic periodontitis (16 males and 12 females), aged 27 to 60 years (mean age $39 \pm 8.8$ ) with severe generalized periodontal lesions classified according to the American Academy of Periodontology ${ }^{1} ; 10$ individuals with gingivitis (6 males and 4 females), aged 24 to 50 years (mean age $29 \pm$ 7.9); and 21 individuals without any sign periodontal disease (9 males and 12 females), aged 24 to 47 years (mean age $30 \pm$ 6.2). Individuals previously treated for periodontal diseases, smokers, pregnant women, and users of antiinflammatory and antibiotic drugs within 3 of the screening procedure were excluded. The clinical examination was performed using a Williams' periodontal probe (Hu Friedy, Chicago, IL, USA) and included the following parameters: bleeding on probing (BOP), clinical attachment level (CAL) and probing depth (PD) at six sites per tooth.

The participants signed an informed consent form approved by Institutional Ethics in Research Committee of the State University of Feira de Santana, BA, Brazil (Protocol no. 013/2002).

\section{Serum Samples}

At clinical examination, blood samples were obtained from all individuals by venipuncture and allowed clotting at the room temperature. Serum was removed after clot centrifugation and stored in small aliquots at $-70^{\circ} \mathrm{C}$ until use.

\section{Bacterial Strain and Culture Conditions}

P. gingivalis ATCC 33277 cells were grown by batch culture to late log phase in Brucella broth supplemented with yeast extract $(0.5 \%)$, L-cysteine $(0.05 \%)$, hemin $(0.5 \%)$ and vitamin $\mathrm{K} 1(0.1 \%)$ in an atmosphere of $85 \% \mathrm{~N}_{2}, 5 \% \mathrm{CO}_{2}$, $10 \% \mathrm{H}_{2}$ at $37^{\circ} \mathrm{C}$. Culture purity was determined by Gram staining and respiratory test.

\section{Preparation of Antigens}

The cells were harvested by centrifugation $(8,000 \mathrm{x} g$ for $30 \mathrm{~min}$, at $4^{\circ} \mathrm{C}$ ) and washed three times with phosphate buffered saline (PBS) 0.15M, pH 7.4. The pellet was resuspended in $5 \mathrm{~mL}$ of PBS containing $185-\mu \mathrm{L}$ protease inhibitor cocktail (Sigma P-8465; Sigma Chemical Co., St. Louis, MO, USA) and subjected to ultrasonic disruption at output 3 (Bronson Sonifier; Bronson Sonic Power Co., Danbury, CT, USA) for 20 minutes. During sonication, the cells were kept at $4^{\circ} \mathrm{C}$ with 1-min cooling period following each 1-min burst of sonication. Disruption was confirmed by Gram staining. Cell debris was removed by centrifugation $\left(13,000 \mathrm{x} g\right.$ for $30 \mathrm{~min}$, at $\left.4^{\circ} \mathrm{C}\right)$ and the sonicated extract fraction was obtained and stored at $-70^{\circ} \mathrm{C}$ until tested.

Protein concentration of the suspension was determined by using a Bio-Rad Protein Assay Kit (Bio-Rad Laboratories, Hercules, CA, USA), with bovine serum albumin (BSA) as standard.

\section{Enzyme-Linked Immunosorbent Assay (ELISA)}

The sera levels of IgG antibodies specific for the bacterial antigens in the sonic extracts were determined using indirect ELISA. Briefly, the sonicated extract was suspended in 0.05 M carbonate buffer (pH 9.6) at $10 \mu \mathrm{g} / \mathrm{mL}$. A 50- $\mu \mathrm{L}$ aliquot of this suspension was placed in each well of a flat-bottomed microplate (Maxisorp, Nunc, Denmark) and incubated overnight at $4^{\circ} \mathrm{C}$. The plate was washed 2 times with PBS containing $0.05 \%$ Tween-20 (PBS-T). All wells were blocked by exposure to $200 \mu \mathrm{L}$ of $1 \%$ BSA in PBS-T at $37^{\circ} \mathrm{C}$ in a moist chamber for $2 \mathrm{~h}$ at $37^{\circ} \mathrm{C}$. Before being tested, each well was washed with PBS-T. A 50- $\mu \mathrm{L}$ aliquot of serum samples diluted in PBS-T containing $0.5 \%$ de BSA $(1: 1,000)$ were added to each well (each serum was added to two antigen-coated wells). After incubation at $37^{\circ} \mathrm{C}$ for $1 \mathrm{~h}$, the plate was washed 5 times with PBS-T. $50 \mu \mathrm{L}$ of a 1:50,000 dilution of peroxidaseconjugated rabbit anti-human IgG immunoglobulin (Sigma A-8792; Sigma Chemical Co., St. Louis, MO, USA), in PBS$\mathrm{T}$ was added per well and incubated at $37^{\circ} \mathrm{C}$ in a moist chamber for $1 \mathrm{~h}$. After the wells had been washed 5 times with PBS-T, $50 \mu \mathrm{L} /$ well of a solution $(10 \mathrm{~mL}$ of citrate buffer pH 5.6 supplemented with $4 \mathrm{mg}$ o-phenylene-diamine and $30 \%$ hydrogen peroxide) were incubated at room temperature for $15 \mathrm{~min}$. When color change was noticed, a $25 \mu \mathrm{L}$ aliquot of $4 \mathrm{~N} \mathrm{H}_{2} \mathrm{SO}_{4}$ was added to stop the reaction.

The absorbance at $490 \mathrm{~nm}$ was measured using a microplate reader (Bio-Rad model 550; Bio-Rad, Hercules, CA, USA). The cut off value of this ELISA was determined by using the receiver operating characteristic curve (ROC Curve)

\section{SDS-PAGE}

Sodium dodecyl sulphate polyacrylamide gel electrophoresis was carried out by the Laemmli $^{7}$ (1970) method, using a stacking gel containing $4 \%$ acrylamide, while the separating gel contained $12 \%$ acrylamide. The $P$. gingivalis antigens were suspended in the sample buffer (1 M Tris-HCl, pH 6.8, 2\% SDS, 10\% glycerol, 5\% mercaptoethanol and $0.025 \%$ bromphenol blue) and were placed in boiling water for $5 \mathrm{~min}$ and $70 \mu \mathrm{g}$ of protein/ lane was added to the gel. Electrophoresis was carried out at a constant current of $30 \mathrm{~mA}$ / gel and was terminated exactly when the bromophenol blue dye front reached the lower end of the separating gel.

Separation of proteins in sonicated $P$. gingivalis cell extracts by SDS-PAGE was observed in $0.75 \mathrm{~mm}$ gel using Coomassie brilliant blue staining R-250 (Sigma Chemical Co., St. Louis, MO, USA). The molecular weight was determined by using the calibration curve established with the low molecular weight calibration kit (protein standards: phosphorylase b (94 kDa), bovine serum albumin (67 kDa), ovalbumin (43 kDa), carbonic anhydrase (30 kDa), soybean trypsin inhibitor (20.1 kDa) and a-lactalbumin (14.4 kDa). 


\section{Western Blotting}

Following electrophoresis, the separated bands were transferred to a nitrocellulose membrane (Millipore ${ }^{\circledR}$; Millipore Corp. Billerica, MA, USA) in Tris-glycine buffer containing $20 \%$ de methanol, $\mathrm{pH} 8.3$ for $1 \mathrm{~h}$ at $100 \mathrm{~V}$. Nonspecific binding was blocked using 5\% BSA in PBS-T overnight at $4^{\circ} \mathrm{C}$. After the membrane had been washed 5 times with PBS-T, individual strips were incubated overnight with serum samples diluted in PBS-T containing $0.5 \%$ de BSA (1:1.00). After strips had been washed 8 times with PBS-T, peroxidase-conjugated rabbit anti-human IgG immunoglobulin (Sigma A-8792), diluted 1:500 in PBS-T containing $0.5 \%$ BSA, was added for $1 \mathrm{~h}$ at 37.The strips were washed again 8 times with PBS-T. The bands were visualized by a substrate solution of $0.3 \%$ of 4 -chloro-1naphtol ( $3 \mathrm{mg} / \mathrm{mL}$ in methanol) diluted 1:5 in PBS containing $0.33 \mu \mathrm{L}$ of $30 \%(\mathrm{v} / \mathrm{v}) \mathrm{H}_{2} \mathrm{O}_{2}$, and then they were rinsed with distilled water and dried. The molecular weights of peaks were calculated.

\section{Statistical Analysis}

Differences between antibody levels in each group (chronic periodontitis, gingivitis and healthy individuals) were evaluated using two-tailed Kruskal-Wallis test. The Mann-Whitney U test was used to examine the serological dichotomy among individuals of the chronic periodontitis group. Spearman's rank correlations were made between serum IgG levels against the cell sonicate antigen from $P$. gingivalis and clinical parameters. The statistical significance was considered for $p$ values lower than 0.05 . Statistical analyses were performed on a computer using a statistical software (Statistical Package for Social Sciences for Windows 11.0; SPSS Inc, Chicago, IL, USA).

\section{RESULTS}

\section{Antibacterial Antibody Levels}

The cutoff value of the ELISA test was determined (0.324) using the coordinate points of the ROC curve, establishing $89.3 \%$ sensitivity and 93.5 specificity, positive predictive value of $92.5 \%$ and negative predictive value of $90 \%$.

Serum IgG levels against cell sonicate antigens from $P$. gingivalis, evaluated by ELISA, were significantly higher in the $\mathrm{CP}$ group when compared to the $\mathrm{G}$ and $\mathrm{H}$ groups. Differences between the CP, $\mathrm{G}$ and $\mathrm{H}$ groups were evaluated using two-tailed (Kruskal-Wallis $\mathrm{p}<0.001$ ), and post Dunnet $\mathrm{t} 3 \mathrm{p}=0.001$ and Dunnet $\mathrm{t} 3 \mathrm{p}=0.0001$ ). There was no statistically significant difference between $\mathrm{G}$ and $\mathrm{H}$ reactivity (Dunnett $\mathrm{t} 3 \mathrm{p}=0.617$ ). Serological dichotomy among CP group individuals was observed. A clear-cut distinction of the CP patients into two subgroups was observed according to their antibody reactivity to $P$. gingivalis. Individuals showing low levels of antibodies (OD $\leq 0.5$ ) were considered to be representative of a low-reactivity chronic periodontitis (LRCP) subgroup. Individuals showing high levels of antibodies (OD $>0.5$ ) were considered to represent a high- reactivity chronic periodontitis (HRCP) subgroup. There was also a highly significant difference (Mann-Whitney U test $\mathrm{p}<0.01$ ) between the LRCP and HRCP subgroups (Figure 1).

Serum IgG levels against $P$. gingivalis of the $\mathrm{CP}$ group and two clinical variables - percentage of the clinical attachment level (CAL) and percentage of pocket depth (PD) - were considered for correlation analysis. Figure 2A shows a positive relationship between serum IgG levels and the percentage of attachment level $\geq 5 \mathrm{~mm}\left(\mathrm{r}_{\mathrm{s}}=+0.375 ; \mathrm{p}<0.05\right)$. In addition, serum IgG levels were correlated to percentage of probing depth $\leq 3 \mathrm{~mm}$ within the CP group $\left(\mathrm{r}_{\mathrm{s}}=-0.411\right.$; $\mathrm{p}<0.05$ ) (Figure 2B). Table 1 shows the distribution of Clinical and Immunological patterns in the two subgroup of patients with chronic periodontitis (LRCP and HRCP).

\section{Profile of Sonicated Cell Extract Proteins of $\boldsymbol{P}$. gingivalis ATCC33277 on SDS-PAGE}

Electrophoretic fractionation of proteins from soluble extract of $P$. gingivalis cells ATCC33277 on SDS-PAGE is shown on Figure 3. The presence of bands with molecular weight approximately between $128 \mathrm{kDa}$ and $15 \mathrm{kDa}$ can be observed. The most intense bands were those with $39 \mathrm{kDa}$, $42 \mathrm{kDa}, 58 \mathrm{kDa}, 72 \mathrm{kDa}$ and $103 \mathrm{kDa}$.

\section{Difference in the Reactivity Pattern by Western Blotting}

Sera from 15 patients of the CP group (8 HRCP and 7 LRCP), 5 of the $G$ group and 6 of the $H$ group were analyzed by western blotting. The absence/presence of specific bands was qualitatively determined to compare the reactivity pattern of serum samples from individuals with chronic periodontitis that exhibit high and low levels in the ELISA test, to the pattern of serum samples from patients with gingivitis and periodontally healthy patients (Figure 4).

The frequency of recognition of bands by serum of HRCP individuals was: approximately $128 \mathrm{kDa}(37.5 \%), 103$ $\mathrm{kDa}(75 \%), 86 \mathrm{kDa}(50 \%), 72 \mathrm{kDa}(75 \%), 60 \mathrm{kDa}(87.5 \%), 58$ $\mathrm{kDa}(37.5 \%), 52 \mathrm{kDa}(72.5 \%), 48 \mathrm{kDa}(62.5 \%), 46 \mathrm{kDa}(25 \%)$, $42 \mathrm{kDa}(25 \%), 39 \mathrm{kDa}(50 \%), 31 \mathrm{kDa}(62 \%), 30 \mathrm{kDa}(25 \%), 26$ $\mathrm{kDa}(25 \%), 24 \mathrm{kDa}(25 \%), 20 \mathrm{kDa}$ (25\%). Bands approximately with $128 \mathrm{kDa}, 52 \mathrm{kDa}, 48 \mathrm{kDa}$ and $42 \mathrm{kDa}$ were recognized only by serum of individuals that presented a high response in ELISA (HPCP) (Figure 5).

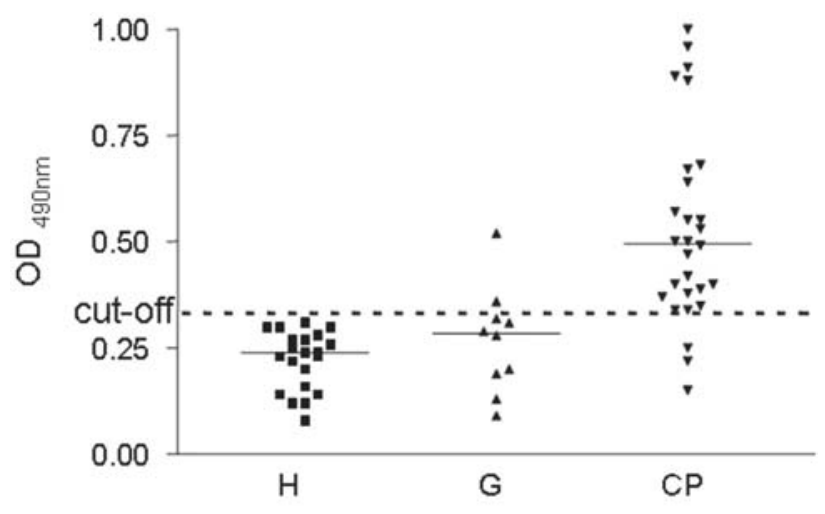

FIGURE 1- Scatter plot showing OD ${ }_{490}$ values after ELISA for IgG antibodies against $P$. gingivalis 


\section{DISCUSSION}

The results of this investigation indicated that patients with chronic periodontitis showed high serum levels of IgG against the soluble extract of $P$. gingivalis ATCC33277 while patients with gingivitis and periodontally healthy individuals presented a weak immunoreactivity to this antigen. This finding is in accordance with the outcomes of several studies, which have demonstrated higher antibody titers in subjects with periodontitis compared to healthy controls ${ }^{4,6,14,16}$.

In the group of individuals with chronic periodontitis, a dichotomy was noted in the results. Although many individuals with chronic periodontitis (57.14\%) have demonstrated high levels of antibodies, 42.85\% presented values below the median. These results match those found by Mouton, et al. ${ }^{9}$ (1987), Ebersole and Steffen ${ }^{5}$ (1995). Although no microbiological analysis was made, low values of IgG against $P$. gingivalis suggest that some individuals with chronic periodontitis present low levels of colonization by these microorganisms, and thus it is possible that other bacterial species predominated in the periodontal lesions of

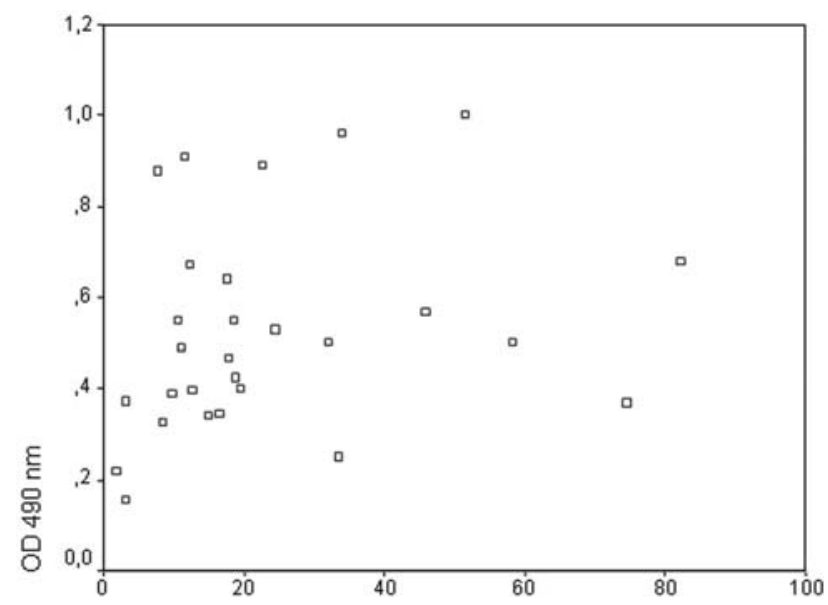

CAL $\geq 5 \mathrm{~mm}$

A approximately half the patients with chronic periodontitis evaluated in this study. It is important to consider the mixed nature of the periodontal infection and multifactorial character of this disease that mainly needs a susceptible host. It is also possible that the dichotomy in the intensity of response is related to a difference between $P$. gingivalis ATCC33277, serotype A, used to obtain the soluble extract and a possible serotype from a $P$. gingivalis species that colonized part of the individuals evaluated. Nevertheless, the other half of individuals with chronic periodontitis was highly responsive to $P$. gingivalis ATCC33277 and the disease could also be associated with an infection by the same serotype.

In the group of individuals with chronic periodontitis, a statistically significant positive correlation was found between the percentage of sites with clinical attachment level $\geq 5 \mathrm{~mm}$ and serum IgG levels against $P$. gingivalis. This means that higher serum IgG levels might be found in samples of individuals with higher percentages of sites presenting attachment level $\geq 5 \mathrm{~mm}$. Analyzing the clinical probing depth, a statistically significant negative correlation

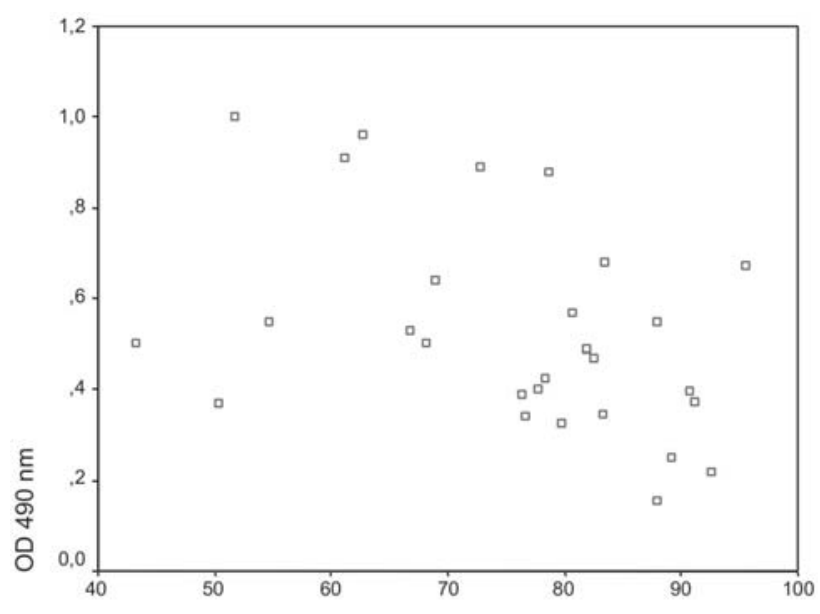

$\operatorname{PD}(0-3 \mathrm{~mm})$

\section{B}

FIGURE 2- $\mathrm{A}$ - Scatter plot showing the correlation between $\mathrm{OD}_{490}$ values after ELISA for IgG antibodies against $P$. gingivalis and percentage of $C A L=5 \mathrm{~mm}$ in patients with periodontitis $\left(r_{s}=+0.375, p<0.05\right)$. B - Scatter plot showing the correlation between $\mathrm{OD}_{490}$ values after ELISA for IgG antibodies against $P$. gingivalis and percentage of PD 0-3 mm in periodontitis patients $\left(r_{s}=-0.411, p<0.05\right)$

TABLE 1- Clinical and Immunological patterns of patients with chronic periodontitis (LRCP and HRCP)

\begin{tabular}{|c|c|c|c|c|c|c|c|}
\hline & IgG Serum Levels & \multicolumn{3}{|c|}{$\%$ Sites with PD $(\mathrm{mm})^{a}$} & \multicolumn{3}{|c|}{$\%$ Sites with CAL $(\mathrm{mm})^{a}$} \\
\hline & & $0-3$ & $4-6$ & $\geq 7$ & $0-2$ & $3-4$ & $\geq 5$ \\
\hline LRCP $(n=16)$ & $0.329 \pm 0.125$ & $78 \pm 14$ & $17 \pm 11$ & $5 \pm 5$ & $47 \pm 19$ & $32 \pm 11$ & $21 \pm 20$ \\
\hline $\operatorname{HRCP}(n=12)$ & $0.736 \pm 0.179$ & $71 \pm 14$ & $22 \pm 10$ & $7 \pm 9$ & $42 \pm 17$ & $30 \pm 19$ & $28 \pm 22$ \\
\hline
\end{tabular}

OD: optical density; ${ }^{a}$ Mean \pm standard deviation; PD: pocket depth; CAL: clinical attachment level; LRCP: patients with chronic periodontitis showing low humoral response by ELISA; HRCP: patients with chronic periodontitis showing high humoral response by ELISA. 


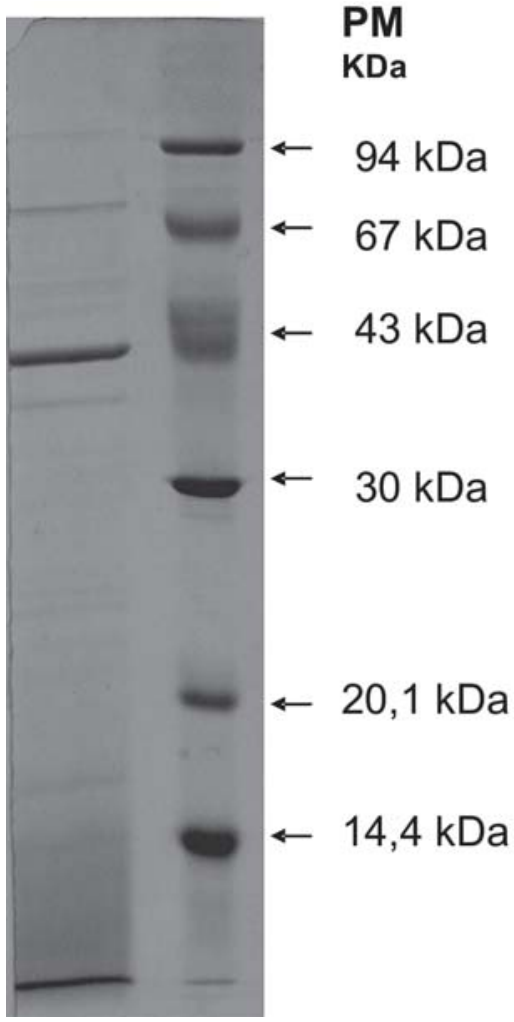

FIGURE 3- SDS-PAGE profiles of sonicated cell extracts from $P$. gingivalis ATCC 33277 . The separated proteins were stained by Coomassie Brilliant Blue was found between the percentage of sites with probing depth (PD) 0-3 mm and levels of serum IgG anti-P. gingivalis. This means that low levels of serum IgG anti- $P$. gingivalis can be found in samples of subjects with high percentages of sites presenting PD between $0-3 \mathrm{~mm}$, values that are compatible with periodontal health. A feasible explanation for this inverse correlation would be the influence of environmental conditions, mainly the redox potential in areas with PD 0-3mm. The present findings also suggest the possibility that high levels of serum IgG are associated with the pathogenesis of periodontitis

Ebersole and Steffen ${ }^{5}$ (1995), investigated the humoral response in humans against antigens of the external membranes of different $P$. gingivalis serotypes. They identified 12 antigenic bands of $P$. gingivalis ATCC33277 of 10-120 kDa (80,72, 68, 52, 44, 42, 31, 20, 16, 14, 13, $12 \mathrm{kDa}$ and a band complex from $83-120 \mathrm{kDa}$ ), and the most intense bands were those with $82 \mathrm{kDa}, 72 \mathrm{kDa}, 58 \mathrm{kDa}, 39 \mathrm{kDa}, 23 \mathrm{kDa}, 12$ $\mathrm{kDa}$. These authors found that most of these antigens were detected in more than $50 \%$ of individuals with periodontitis, who showed high response in ELISA. The band complex from $83-120 \mathrm{kDa}$ was significantly more frequent in this group compared to other individuals.

In the present study, bands of molecular weight approximately 103, 86, 72, 60, $58 \mathrm{kDa}$, presented more than $50 \%$ frequency of reactivity by the serum of patients with periodontitis when compared to the groups $\mathrm{H}$ and $\mathrm{G}$. On the other hand, bands with a low molecular weight, approximately

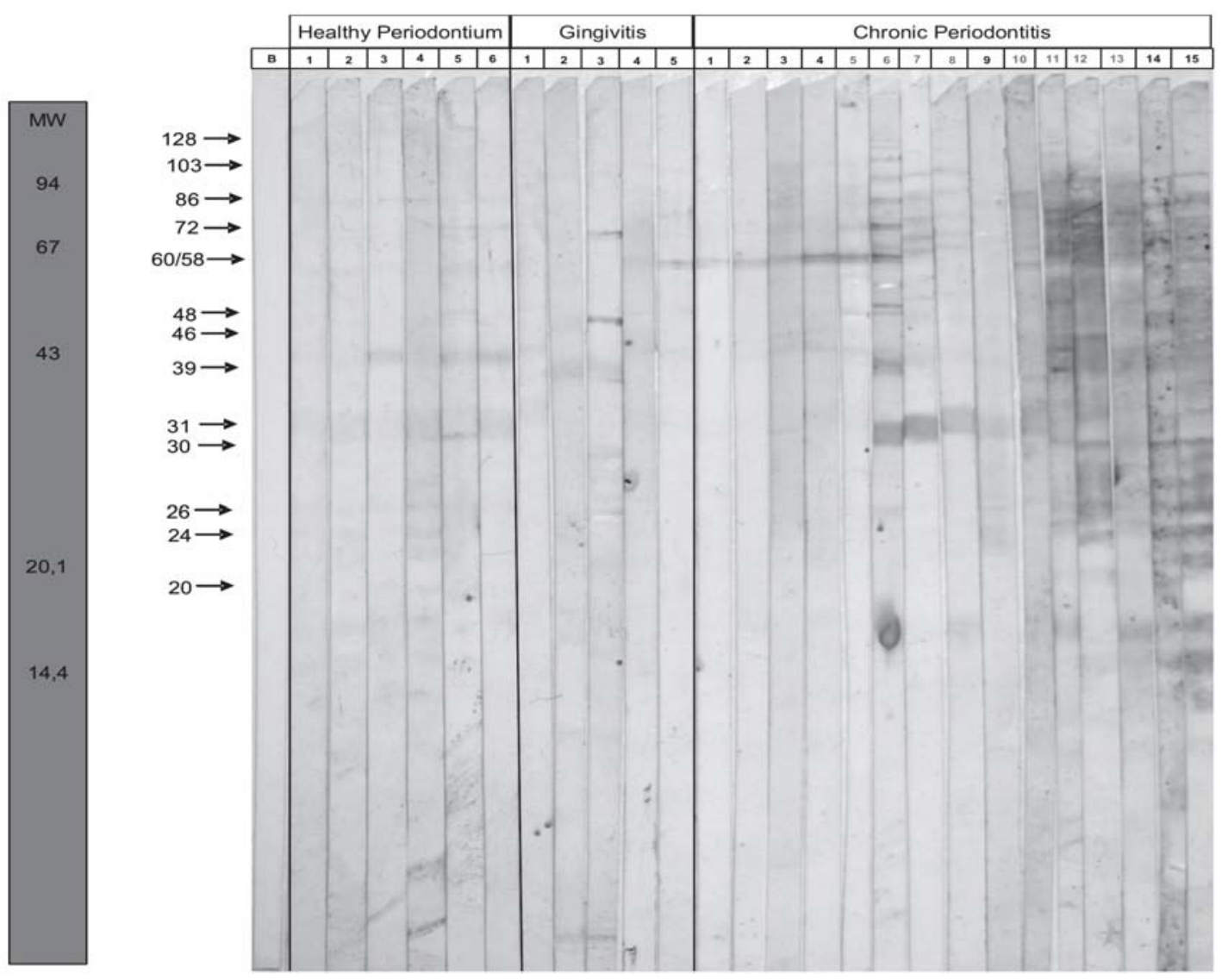

FIGURE 4- Western immunoblotting of serum sample from 15 patients with chronic periodontitis, 5 patients with gingivitis and 6 periodontally healthy individuals 


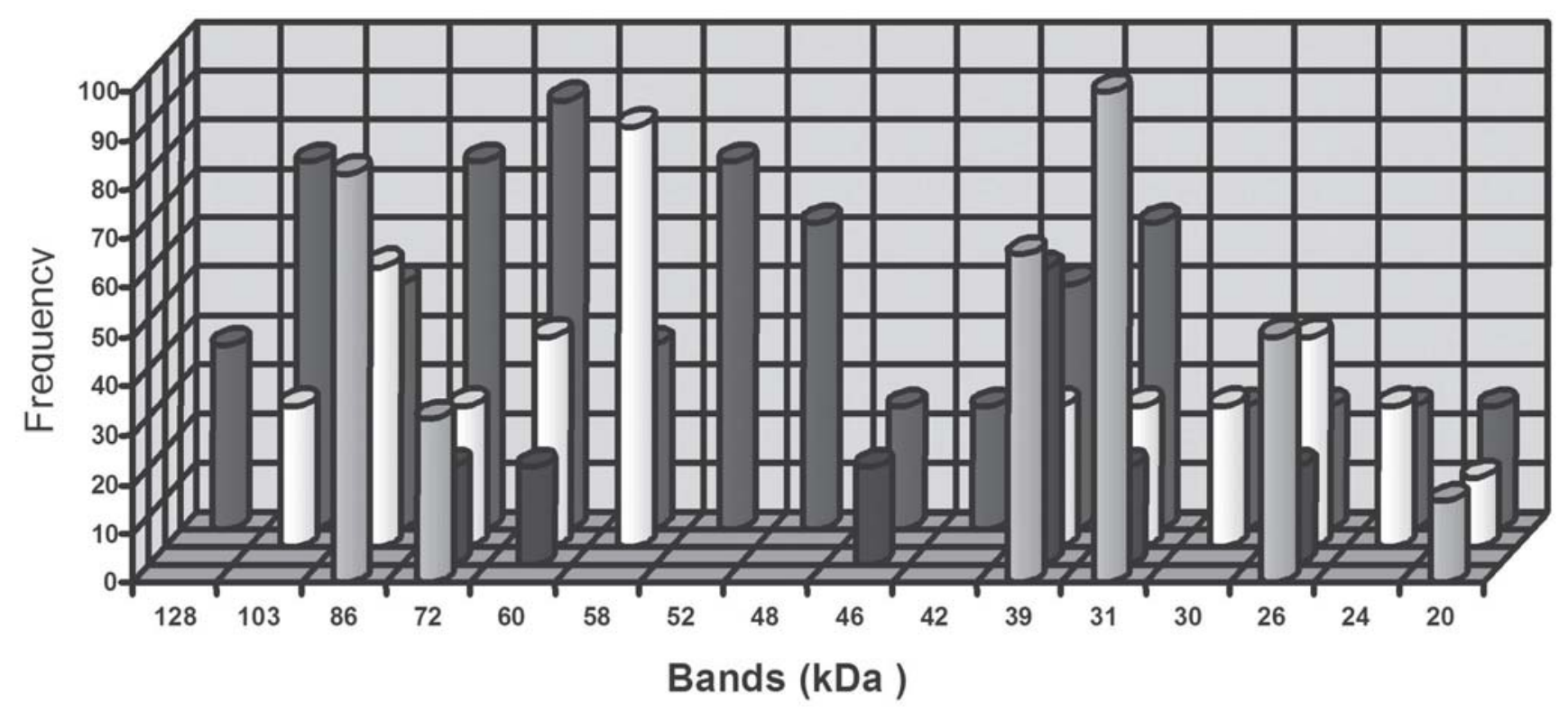

DH DG DLRCP QHRCP

FIGURE 5- Band recognition frequencies in each individual group - healthy periodontium (H), gingivitis (G), low-response chronic periodontitis (LRCP) and high-response chronic periodontitis (HRCP)

$39 \mathrm{kDa}$ and $31 \mathrm{kDa}$, presented a higher frequency of reactivity in the groups $\mathrm{G}$ and $\mathrm{H}$ compared to the serum of individuals in the CP group, which indicates non-specificity to these protein fractions. Under the studied conditions, bands of approximately $128 \mathrm{kDa}, 52 \mathrm{kDa}, 48 \mathrm{kDa}$ and $42 \mathrm{kDa}$ were recognized only by serum from individuals that presented a high response in ELISA (HPCP).

\section{CONCLUSIONS}

In conclusion, using the standardized indirect ELISA test it was possible to distinguish the group of individuals with chronic periodontitis from the group of individuals with gingivitis and the healthy patients by means of IgG anti $P$. gingivalis serum levels. A positive correlation was observed between IgG anti- $P$. gingivalis serum levels and the progression of chronic periodontitis, when the clinical attachment level was evaluated. The present results showed that there was significant difference in the recognition profile of protein fractions among studied groups and that some bands are more specific. However, to identify the immunodominant antigens of the soluble extractum of $P$. gingivalis used in this study, a posterior analysis of samples by Western blotting with serial dilutions of serum is suggested. Furthermore, posterior purification and identification of immunodominant components are suggested because it may be important for determining the significance of these antigenic components in the interaction with the host. It can be helpful to the serological diagnoses in periodontal disease.

\section{ACKNOWLEDGEMENTS}

The authors thank Dr. Vela Lúcia Costa Vale (Bahia State University), Dr. Bruno Paule (Agriculture Ministry) and Dr. Maria Olímpia Villas-Boas (Bahia State Foundation for the Development of Sciences) for making it possible the development of this research. The authors are also grateful to Dr. Luís de Macedo Farias and Dr. Maria Auxiliadora Roque de Carvalho for the acquired knowledge and shelter at the Anaerobic Laboratory of the Federal University of Minas Gerais.

\section{REFERENCES}

1- American Academy of Periodontology. Consensus report. Chronic periodontitis. Ann Periodontol. 1999;4:53.

2- Berglundh T, Donati M. Aspects of adaptive host response in periodontitis. J Clin Periodontol. 2005;32 Suppl 6:87-107.

3- Boutsi EA. Analysis of immunodominant antigens of Porphyromonas gingivalis 381 in high responder patients. Bull Tokyo Med Dent Univ. 1993;40:45-58.

4- Dye BA, Choudhary K, Shea S, Papapanou PN. Serum antibodies to periodontal pathogens and markers of systemic inflammation. J Clin Periodontol. 2005;32:1189-99.

5- Ebersole JL, Steffen MJ. Human antibody responses to outer envelope antigens of Porphyromonas gingivalis serotypes. J Periodont Res.1995;30:1-14.

6- Graswinckel J, van Der Velden U, van Winkelhoff A, Hoek F, Loos B. Plasma antibody levels in periodontitis patients and controls. J Clin Periodontol. 2004;31:562-8. 
7- Laemmli U. Cleavage of structural proteins during the assembly of the head of bacteriophage t4. Nature. 1970;227:680-5.

8- Mooney J, Kinane DF. Humoral immune responses to Porphyromonas gingivalis and Actinobacillus actinomycetemcomitans in adult periodontitis and rapidly progressive periodontitis. Oral Microbiol Immunol. 1994;9:321-6.

9- Mouton C, Desclauriers M, Bouchard M. Serum antibodies to Bacteroides gingivalis in periodontitis: a longitudinal study. J Periodont Res. 1987;22:426-30.

10- Page RC. Vaccination and periodontitis: myth or reality. J Int Acad Periodontol. 2000;2:31-43.

11- Petit MD, van Steenbergen TJM, Timmerman MF, de Graaff J, van der Velden U. Prevalence of periodontitis and suspected periodontal pathogens in families of adult periodontitis patients. J Clin Periodontol. 1994;21:76-85.

12- Plombas M, Bernard G, De March AK, Sarda M, Sixou M, Bené Mc, et al. Isotypic antibody response to plaque anaerobes in periodontal diseases. J Periodontol. 2002;73:1507-11.

13-Tunes U. Perfil imuno-genetico-microbiológico clinico de indivíduos com periodontite crônica [tese]. Salvador (BA): Universidade Federal da Bahia; 2006.

14- Tsurumi Y, Hayakawa M, Shibata Y, Abiko Y. Production of antibody against a synthetic peptide of Porphyromonas gingivalis 40-kDa outer membrane protein. J Oral Sci. 2003;45:111-6.

15- van Dyke TE, Sheilesh D. Risk factors for periodontitis. J Int Acad Periodontol. 2005;7:3-7

16- Yasaki-Inagaki Y, Inagaki S, Yamada S, Okuda K, Ishihara K. Production of protective antibodies against Porphyromonas gingivalis strains by immunization with recombinant gingipain domains. FEMS Immunol Med Microbiol. 2006;47:287-95 